\title{
Preface to the Special Issue on "Taiwan Earthquake Model: Seismic Hazard Assessment and Earthquake Scenario"
}

\author{
Ruey-Juin Rau and Kuo-Fong Ma
}

Citation: Rau, R. J. and K.F.Ma, 2016: Preface to the special issue on "Taiwan Earthquake Model: Seismic hazard assessment and earthquake scenario". Terr. Atmos. Ocean. Sci., 27, I-III, doi: 10.3319/TAO.2016.06.01.01(TEM)

With its high strain rate $\left(10^{-6}-10^{-7}\right.$ per year) acting on the oblique subduction-collision transition zone, seismicity in Taiwan is indicated by frequent small and moderate sized earthquakes, and occasionally some $\mathrm{M} \sim 7$ events. During the last century and in recent years, Taiwan experienced a significant number of earthquakes. For example, the 1906 M 7.1 Meishan earthquake, the 1935 M 7.1 Hsinchu-Taichung earthquake, and the 1999 M 7.6 Chi-Chi earthquake. The enormous damage caused by these events progressively compelled us to provide reliable and detailed seismic hazard and risk assessments for the country. With support from the former National Science Council and now the Ministry of Science and Technology and the Taiwan earthquake science communities, the Taiwan Earthquake Model (TEM) organization was established in 2012 under the supervision of the Taiwan Earthquake Research Center (TEC). The main purpose of TEM is to study the probability for seismic hazard and risk analysis for Taiwan by integrating the earthquake science, earthquake engineering, and social science communities of Taiwan. With help from TEM related research, we wish to improve our understanding of Taiwan earthquake mechanisms and therefore provide new insight into seismic hazard and risk assessments for Taiwan.

The seismic hazard model consists of two major components: the seismotectonic model and the ground shaking model (e.g., Campbell et al. 2002), often evaluated through the Probability of Seismic Hazard Assessment (PSHA) approach originally proposed by Cornell (1968). Taiwan seismic hazard assessment research has been practiced at different stages for the last 30 years or so (see Cheng et al. 2015 and references therein). The 1999 Chi-Chi earthquake played an important role in the model verification and modifications. With contributions from this special issue, we collect and document the up-to-date efforts on seismic hazard assessment and earthquake scenario studies for Taiwan.

Shyu et al. (2016) combined previously published data and their field survey results to construct a database with parameters, such as the long-term slip rate and recurrence intervals for 38 on-land active seismogenic structures in Taiwan. They also digitized and provided an updated threedimensional seismogenic structural map of Taiwan. This provides important information for earthquake hazard analy- sis and mitigation. Wang et al. (2016) used the parameters from 38 on-land seismogenic structures proposed by Shyu et al. (2016) area source from the compiled earthquake catalog and subduction zone sources to practice the probability seismic hazard analysis for Taiwan. They found that the areas with highest earthquake hazard probability are southwestern Taiwan and the Longitudinal Valley of eastern Taiwan. Among the densely-populated western Taiwan region, Taichung, Tainan and New Taipei City have high seismic hazard, where Tainan has the highest earthquake hazard probability. For pseudo-spectral acceleration, Tainan has higher hazard over short spectral periods, whereas Taichung has higher hazard over long spectral periods. This analysis indicates the importance of earthquake-resistant designs for low-rise buildings in Tainan and high-rise buildings in Taichung. Lee et al. (2016) utilized the active fault parameters collected by the Central Geological Survey to evaluate the earthquake probabilities in the next 30,50, and 100 years for $M \geq 6.5$ earthquakes to occur in Central Taiwan. They found that the Tachia-Changhua fault system has the highest probability for $\mathrm{M} \geq 6.5$ earthquakes to occur within the next 100 years and the Chelungpu fault has the lowest probability.

Chen et al. (2016) built a crustal-scale shear wave velocity model with a combination of the uppermost "engineering bedrock" and the tomographic crustal velocity models for the western plain of Taiwan and then performed a numerical simulation for wave propagation to verify the velocity model accuracy and importance. Their model demonstrates notable improvements in predicting effective shaking duration and the PGV distribution for ground motion simulation. Chen et al. (2016) deployed a dense short-period seismic network in the South Ilan plain and used these data to perform ambient noise tomography and invert for the high-resolution 3-D shear velocity model for the shallow structure. They found a high velocity anomaly zone for the upper $2 \mathrm{~km}$, corresponding to the exposed metamorphic rocks located south of the South Ilan Plain. On the other hand, the geothermal site, Chingshui is indicated by a low $S$-wave velocity zone for the upper $1.5 \mathrm{~km}$. Yeh et al. (2016) used the data recorded by the Central Weather Bureau Seismic Network and a temporary dense seismic network in the Chiayi area to study the highresolution tomography model of the Chukou fault region. 
They were able to image the fine-scaled imbricate thrust fault system in the Chukou fault zone.

Lee et al. (2016) presented a spatial stochastic model incorporating slipped-area scaling for the near-fault ground motion simulation. They found that, for ground motion prediction the mean slip and characteristic asperity scenario source models may over-predict the near fault ground motion. Their stochastic slip-scaling model instead performed a better prediction for the ground motion. Wen et al. (2016) performed a hybrid ground motion simulation to investigate the source and ground motion characteristics of the 2013 Ruisui earthquake. They demonstrated that, despite the complex structure in eastern Taiwan, their hybrid approach successfully replicated the overall characteristics of broadband ground motion for the 2013 Ruisui earthquake. Liao et al. (2016) performed a hybrid method comprising both the spectral-element and the empirical Green's function methods to simulate the ground motion of the 1909 Taipei earthquake. Their study indicated that the moment magnitude of the 1909 Taipei earthquake was either 7.3 with a stress drop of 30 bars, or between 6.8 and 7.3, but with a higher stress drop of $>100$ bars. Cheng et al. (2016) evaluated the historical documents related to the 1867 Keelung earthquake and tsunami and reconstructed the scenario for this enigmatic event. They suggest that the 1867 Keelung earthquake was most likely activated by the $40-\mathrm{km}$ long offshore portion of the Shanchiao fault and the moment magnitude of the event was 7.0.

Through the collections in this issue, we hope our efforts will advance our research on seismic hazard assessment in Taiwan, and also promote earthquake disaster prevention policy emphasis by the local governments.

Acknowledgements We wish to thank all of the authors who contributed to this special issue and we express our gratitude to the many Reviewers who provided thorough and insightful comments to the manuscripts. This preface was supported by the Ministry of Science and Technology under grants MOST 105-2119-M-006-016.

\section{REFERENCES}

Campbell, K. W., P. C. Thenhaus, T. P. Barnhard, and D. B. Hampson, 2002: Seismic hazard model for loss estimation and risk management in Taiwan. Soil Dyn. Earthq. Eng., 22, 743-754, doi: 10.1016/S0267-7261(02)00095-7. [Link]

Chen, C. T., C. H. Kuo, K. L. Wen, C. M. Lin, and J. Y. Huang, 2016: Simulating shallow soil response using wave propagation numerical modelling in the western plain of Taiwan. Terr. Atmos. Ocean. Sci., 27,359-373, doi: 10.3319/TAO.2016.01.06.01(TEM). [Link]

Chen, K. X., P. F. Chen, L. W. Chen, H. Yao, H. Fang, and P. L. Su, 2016: South Ilan Plain high-resolution 3-D $S$-wave velocity from ambient noise tomography. Terr. Atmos. Ocean. Sci., 27, 375-385, doi: 10.3319/ TAO.2016.01.29.02(TEM). [Link]

Cheng, C. T., P. S. Hsieh, P. S. Lin, Y. T. Yen, and C. H. Chan, 2015: Probability seismic hazard mapping of Taiwan. Encyclopedia of Earthquake Engineering, Springer Berlin Heidelberg, 25 pp, doi: 10.1007/9783-642-36197-5_100-1. [Link]

Cheng, S. N., C.F. Shaw, and Y. T. Yeh, 2016: Reconstructing the 1867 Keelung earthquake and tsunami based on historical documents. Terr. Atmos. Ocean. Sci., 27, 431-449, doi: 10.3319/TAO.2016.03.18.01(TEM). [Link]

Cornell, C. A., 1968: Engineering seismic risk analysis. Bull. Seismol. Soc. Am., 58, 1583-1606.

Lee, Y. R., C. T. Cheng, K. S. Shao, Y. R. Chuang, J. C. Hu, T. H. Lai, and S. T. Lu, 2016: Earthquake probability assessment for the active faults in Central Taiwan: A case study. Terr. Atmos. Ocean. Sci., 27, 341-357, doi: 10.3319/TAO.2016.03.24.01(TEM). [Link]

Lee, Y. T., K. F. Ma, M. C. Hsieh, Y. T. Yen, and Y. S. Sun, 2016: Synthetic ground-motion simulation using a spatial stochastic model with slip self-similarity: Toward near-source ground-motion validation. Terr. Atmos. Ocean. Sci., 27, 397-405, doi: 10.3319/ TAO.2015.11.27.01(TEM). [Link]

Liao, Y. W., Y. T. Yen, S. J. Lee, and K. F. Ma, 2016: 1909 Taipei earthquake ground motion simulation. Terr. Atmos. Ocean. Sci., 27, 415-430, doi: 10.3319/ TAO.2016.03.02.01(TEM). [Link]

Shyu, J. B. H., Y. R. Chuang, Y. L. Chen, Y. R. Lee, and C. T. Cheng, 2016: A new on-land seismogenic structure source database from the Taiwan Earthquake Model (TEM) project for seismic hazard analysis of Taiwan. Terr. Atmos. Ocean. Sci., 27, 311-323, doi: 10.3319/ TAO.2015.11.27.02(TEM). [Link]

Wang, Y. J., C. H. Chan, Y. T. Lee, K. F. Ma, J. B. H. Shyu, R. J. Rau, and C. T. Cheng, 2016: Probabilistic seismic hazard assessment for Taiwan.Terr.Atmos.Ocean.Sci., 27, 325-340, doi: 10.3319/TAO.2016.05.03.01(TEM). [Link]

Wen, Y. Y., Y. T. Yen, S. Wen, S. J. Lee, C. H. Kuo, and Y. Y. Lin, 2016: Hybrid ground motion simulation for the $2013 \mathrm{M}_{\mathrm{L}}$ 6.4 Ruisui, Taiwan earthquake. Terr. Atmos. Ocean. Sci., 27, 407-414, doi: 10.3319/ TAO.2015.10.30.01(TEM). [Link]

Yeh, Y. L., S. Wen, W. C. Chien, Y. Z. Chang, and C. H. Chen, 2016: Tomography of the Chukou Fault zone, southwest Taiwan: Insights from microearthquake data. Terr. Atmos. Ocean. Sci., 27, 387-396, doi: 10.3319/ TAO.2016.01.29.01(TEM). [Link] 


\section{Responsible Editor:}

Cheng-Horng Lin

Institute of Earth Sciences, Academia Sinica, Taipei, Taiwan, R.O.C.

E-mail: lin@earth.sinica.edu.tw

\section{Guest Editor:}

Kuo-Fong Ma

Department of Earth Sciences, National Central University,
Taoyuan City, Taiwan, R.O.C.

E-mail: kuofongm@gmail.com

\section{Executive Guest Editor:}

Ruey-Juin Rau

Department of Earth Sciences, National Cheng Kung University, Tainan City, Taiwan, R.O.C.

E-mail: raurj@mail.ncku.edu.tw 